\section{TELEVISION-PAST AND FUTURE}

$\mathbf{A}^{\mathrm{s}}$ S we are able to look forward to conditions of peace in Europe, it is natural for our thoughts to turn towards the resumption of many of the amenities of civilized life, which has been so seriously restricted during the War. Among these amenities is the reception of television programmes for instructional and entertainment purposes, a service which was provided by the London Television Station over a limited area of Great Britain for a year or two preceding the outbreak of war. In view of the widespread application of radio technique to military purposes, and the outstanding advances made in various directions during the past five years, it is natural to inquire in what way and to what extent radio broadcasting and television will benefit when this technique and the personnel trained in its use are directed to the exploitation of these peacetime pursuits. It is therefore relevant to refer in some detail to an address entitled "Some Aspects of Pre-War and Post-War Television" given to the Royal Institution on March 2 by Mr. H. L. Kirke, head of the Research Department of the British Broadcasting Corporation.

This address surveyed the general principles of modern television practice and the technical features and requirements; $\mathrm{Mr}$. Kirke also directed attention to the various problems which must be solved before certain developments and improvements, which have been foreshadowed in some quarters, can be incorporated in a reliable service for the public needs.

\section{Picture Scanning}

Whatever system is employed for the transmission of a television picture, basic necessities are the analysis of the picture or scene at the transmitting end, and its synthesis at the receiving end. Thus the picture or scene is broken down into a number of small elements, so that the degree of light or shade, or even colour, of each element can be transmitted independently and reassembled in the correct order at the receiving end. The degree of distortion of the picture, or its complement the definition, will depend upon the number of elements into which the picture is divided, and the size of the resultant received picture as it appears to the eye of the viewer.

The usual arrangement for scanning a picture is to divide it in effect into a number of horizontal lines, each of which is scanned or seen by the television apparatus, element by element, usually from left to right. The scanning of a picture in this way can be visualized by imagining it to be divided into a number of strips, the right-hand end of one strip being joined to the left-hand end of the strip below to form one continuous strip. This strip can now be considered as passing a slit through which elements of the picture can be exposed to a photo-electric cell as the strip passes by. The current output from the photo-electric cell at any instant is a function of the average amount of light falling upon the cell at that instant, so that the definition in the horizontal plane depends upon the size of slit or aperture, while the definition in the vertical plane is a function of the line width and therefore of the number of lines. When the scanning is done with a square or round aperture, the definitions in the vertical and horizontal directions are the sarne, and this is the usual arrangement. For the transmission of moving pictures, the whole field of view must be repeatedly scanned at a rate exceeding twenty-five pictures per second, in order that the eye shall not be conscious of flicker, a condition corresponding to practice in cinematography.

The sharpness or definition of a picture depends upon the number of elements into which it is divided for scanning purposes; and the radio-frequency band width occupied by the transmission of a picture depends upon the number of picture elements per second. The London Television Station at Alexandra Palace, before the War, transmitted pictures divided into 405 lines at the rate of twenty-five pictures per second, and these occupied a radio-frequency channel of 5 megacycles per second wide. By the use of a device known as interlaced scanning, it is possible to transmit a 405-line picture with only twenty-five complete pictures per second in such a manner that the flicker corresponds to fifty pictures per second. Interlaced scanning is achieved by scanning alternate lines of a picture in sequence followed by the scanning of the remaining intermediate lines. The repetition rate or flicker frequency is therefore twice the actual number of complete pictures per second. Thus alternate 'frames', as they are called in Britain, consist of $202 \frac{1}{2}$ lines each, while a complete picture of two frames comprises 405 lines. Interlace ratios other than two are possible but not usual in black and white television.

\section{Electron Cameras}

Although mechanical scanning systems have been developed and may still have possibilities, the more usual method makes use of a beam of electrons for the scanning process. The picture or scene to be transmitted is focused on a plate which comprises a mosaic of minute photo-electric cells, each of which acquires a positive charge to an extent depending upon the amount of light falling upon it. A beam of electrons is caused to traverse this mosaic in the scanning process, and at every point the current in the beam is proportional to the amount of light falling upon the corresponding photo-electric element. The resulting electric impulses are used to modulate the radio-frequency carrier wave of the television transmitter. The electron camera tube, particular versions of which are known as the 'emitron' in Britain, and the 'iconoscope' in the United States, is thus the link that converts the visual picture into electric signalling impulses. There have been a number of developments in electron devices and electron optics both in Britain and in the United States during and before the War which will undoubtedly be of considerable value in the further development of television camera tubes, and it is to be hoped that the considerable development of miniature components will enable the size of mobile television cameras to be reduced, as well as the size of apparatus for use in connexion with outside broadcasts.

\section{Reception}

At the receiving end the impulsive modulation is extracted from the incoming carrier wave, and used to vary in some way the intensity of light falling upon the viewing screen. The most widely used method of display before the War was the cathode ray tube, and it is probable that for a considerable time this will prove to be the cheapest and most popular form for home-viewing. The amount of development and the knowledge which has become available during the War will undoubtedly be of assistance in the improvement of the performance of cathode ray tubes, and 
mass production methods should be effective in reducing the cost.

The main limitation of the cathode ray tubes is the size of pictures which can be obtained. Pictures ranging from 5 in. $\times 4$ in. to 10 in. $\times 8$ in. were normally obtainable in commercial receivers, the former on cheaper sets and the latter on the more expensive sets. Even larger tubes have been made and used, and it is of interest to note that one firm in the United States has advertised that cathode ray tubes suitable for pictures nearly double that size will be available after the War. Whether these will be a commercial proposition remains to be seen. For large-screen operation a number of methods have been used. Most of these employ some form of small cathode ray tube with high intensity beam and a fluorescent screen from which the picture is projected on to a larger screen. Such devices have the disadvantage of being more costly and require very high voltages for their operation.

\section{Programme Distribution}

Now, it has already been explained that the radiofrequency band-width required for an effective television transmission is about $\pm 2.5 \mathrm{Mc} / \mathrm{s}$., as compared with \pm 10 or $15 \mathrm{kc} . / \mathrm{s}$. for good-quality sound broadcasting. To transmit the larger band required for a medium definition television system necessitates the use of a carrier frequency in the neighbourhood of $50 \mathrm{Mc} . / \mathrm{s}$., corresponding to a wave-length of 6 metres. The use of such a short wave-length restricts the range of reliable reception to some $30-50$ miles, depending upon the $h$ jight of transmitter and receiver and the existence of intervening hills, trees and buildings. With such a limitation on the range of transmission, it is clearly necessary to have several transmitting stations if the programmes are to be received in various parts of Britain.

The problem of communicating programmes from one station to another has received considerable attention, since the use of ordinary telephone cables to transmit the wide band of frequencies required is not very practicable. Special co-axial cables have been developed for this purpose, and preliminary work has also taken place on the use of radio links for point-to-point transmission. In each case, however, it is necessary to have amplifiers or repeater stations at five to thirty miles apart, so that the problem of relaying programmes over a distance of four hundred miles, such as from London to Glasgow, is quite a formidable one. Both cable and radio link methods had, however, been in successful use in Great Britain before the War, for supplying outside broadcast television features from a mobile transmitter developed by the B.B.C.

\section{Future Developments}

There is no doubt that a high-definition television system can be developed, and it would be possible to provide a service for the whole of Great Britain by such a system. Whether this could in fact be done is mainly an economic question. The cost of television programmes is many times that of sound programmes. The cost of television transmission apparatus is considerably greater than that for sound. The number and cost of technical, operational and programme staff is also considerably greater. The cost of distribution, whether by line or radio, will also be greater, and last but by no means least, the cost of the receiver is perhaps one of the most important factors.

\section{Higher Definition}

Mr. Kirke then discussed the question of the definition that is satisfactory for a television service, particularly in connexion with the possible future increase in size of picture for home-viewing. The present American system uses 525 lines and 60 frames per second, but the resulting increase in band width is accommodated in about the same frequency channel of 4-5 Mc./s. by the use of asymmetric side-band transmission. It is doubtful, however, if it is worth while considering an alteration in the British system unless a change is made to 600 , or even 800 lines, with a corresponding increase in horizontal definition. In any event, much experimental development work is required, and it cannot be expected that any new system can be made available as a public service for several years after the end of the War.

One aspect of the subject that may settle the future trend of development is that of the size of picture required for normal home-viewing. At present this size is limited to 10 in. $\times 8$ in.; but it seems reasonable to anticipate the desirability of increasing this to 20 in. $\times 16$ in. For the same viewing distance, this will involve an increase in the definition in both the vertical and horizontal directions, and the resulting increase in scanning speed will require $a$ band-width four times as great as at present. The carrier frequency will have to be correspondingly increased to at least $200 \mathrm{Mc}$./s., a wave-length of one and a half metres or less. The propagation characteristics of such short wave-lengths have certain disadvantages from a general reception point of view : the effect of ground contours and the shadows of hills and trees are more marked; and interference effects by waves reflected from buildings and other objects are more severe. Also, in general, the sensitivity of receivers would be less and the cost probably greater, although by development and mass production this cost might be reduced.

\section{Colour}

Demonstrations have already been given in Great Britain and in the United States of the possibilities of transmitting pictures in colour, which requires the use of two or more basic colours. At the transmitter, filters can be used to separate the colours. In a mechanical system, as used in the United States, a rotating set of colour filters permits the projection of the various colour elements of the scene in turn on one photo-electric screen. The pictures containing the different colour elements are each scanned, and in some cases there is interlacing of the difierent colours. At the recoiving end a similar rotating colour disk is used in conjunction with a cathode ray tube. In the electronic system demonstrated by Mr. J. L. Baird in Great Britain, a two-colour and a three-colour process have been used experimentally. In effect, a separate screen is used for each colour, each screen being scanned by a separate electron beam. In colour television the total number of pictures transmitted per second must be increased as each colour requires a separate scansion; and the increase in number of pictures per second requires a proportional increase in band-width. If the practical limit is the bandwidth employed, it is necessary to compare the advantages of colour with the disadvantages of lower definition.

There is no doubt that colour does give a considerable improvement to the picture. It appears to add another dimension, and provided a certain standard of definition is achieved in any event, then colour is a 
great advantage. This is the experience of those who have experimented with colour photography, and it is certainly true of the cinema, although there are still many who say they prefer black and white.

If it be assumed that for a three-colour system the total number of pictures per second is doubled instead of trebled, then double the band-width is necessary. If the band-width is $10 \mathrm{Mc} / \mathrm{s}$., corresponding with 800 lines for monochrome, then a colour picture could be produced having 565 lines approximately; and a decision as to which was the better would be difficult, for a 565-line picture with colour would give an agreeable degree of definition and a pleasing result.

This point was demonstrated by Mr. Kirke by displaying two still pictures obtained in the United States about a year ago and taken with a mechanical colour switching system using 375 lines and 120 frames per second, the whole picture being accommodated in the standard American band-width of $4 \mathrm{Mc} / \mathrm{s}$. The 375 lines in colour therefore correspond with 525 lines in monochrome: the pictures show that the apparent definition is rather surprising, and the compensating effect of colour is quite noticeable.

\section{FORMATIVE EFFECTS OF ENVIRONMENTAL FACTORS AS EXEMPLIFIED IN THE DEVELOP- MENT OF THE ONION PLANT}

\author{
By DR. O. V. S. HEATH \\ Research Institute of Plant Physiology, Imperial College of \\ Science and Technology, S.W.7
}

$\mathrm{D}$ URING the last two decades, discoveries of great importance have been made in the field of plant morphogenesis, and the predominant part played by the external factors of day-length and temperature has been established. Applications of this knowledge to the control of plant growth in agricultural and horticultural practice have led to important results, for example, in the forcing of bulbs (Blaauw, Van Slogteren and their associates ${ }^{1,2}$ ) and the development of vernalization as a practical technique in the U.S.S.R..$^{3,4,5}$. In both these cases temperature effects are concerned; with regard to the length of day effects ('photoperiodism') the ample empirical knowledge we owe to Garner and Allard and subsequent investigators $^{6}$ has so far yielded fewer practical results than might have been anticipated. The work dealt with in this article has brought to a focus these lines of research in an attempt to elucidate the behaviour of the onion plant.

The physiological investigation of the onion plant in this Institute began five years ago with the primary object of discovering the causes of 'bolting' (flowering) in onions grown from sets and the most satisfactory methods of control. As the work has developed, investigations on the mode of production, storage and use of onion sets have been carried out. The practical recommendations arising from this work are being dealt with elsewhere; the present account is concerned with the physiological effects of the factors of day-length and temperature, and their interactions, in controlling the developmental morphology of the onion plant-especially the processes of bulb formation, and flower initiation and development.

Onions are grown in practice from seed sown in the open, from transplanted seedlings, or from sets.
The latter are small bulbs, produced from seed in one season, stored dry through the winter and planted out in a second season to give a usable crop of large onions. Before the War, considerable quantities were imported, mainly from southern Europe. Their chief disadvantage is their marked tendency to bolt; the bulb produced is then generally small and of little value. In this work, therefore, the practical interest centres on preventing flowering, rather than hastening it as, for example, in vermalization. Bolting may be prevented in a number of ways, but there is little doubt that the most practical method lies in the use of suitable varieties ${ }^{7,8}$ and sets of suitable size $e^{7,8,9}$. Selection of low-bolting strains has been carried out ${ }^{8}$ and re-selection work is being continued.

To provide a background for discussion, a brief description will first be given of the normal lifehistory of an onion plant, covering the whole growth and development from seed to mature harvested bulb, through two growing seasons and the intervening storage period; some of the experimental results will be intercalated as seems appropriate. Except where other references are given, the whole account is based on our own observations; but the development of the seedling (before bulb development) has also been described by Hoffman ${ }^{10}$ and that of the flower by Jones and Emsweller ${ }^{11}$.

\section{Development from Seed to Set}

At germination of the seed the cylindrical cotyledon emerges, and through a pore near the bottom the first foliage leaf later protrudes. Each foliage leaf in turn emerges through a similar pore in its predecessor; the pore thus marks in each leaf the junction of the cylindrical leaf 'blade' and the cylindrical sheathing leaf-base. During development, the first formed portion of the leaf initial gives rise to a pointed structure, the embryonic leaf-blade. This expands both longitudinally and centripetally, over-arching the axis; at the same time the embryonic leaf-base extends round the growing point and completely surrounds it at a very early stage. The pore is thus left on the side of the axis opposite the tip of the leaf blade, and as the phyllotaxy is alternate, is thus in the correct position for the emergence through it of the next leaf in succession (Fig. 1). The leaf blade is at first solid, and only becomes hollow after emergence by the formation of a lysingenous cavity.

Before the onset of bulbing, new leaves emerge about once a fortnight, at ordinary summer temperatures, and there are generally three unemerged leaf initials to be seen at the growing point on dissection (Fig. 1). Under short-day conditions (less than about twelve hours) the plant can apparently continue growing and producing new leaves indefinitely in this way without bulb formation. The older leaves die off ; the pseudo-stem or neck, formed of thin concentric leaf-bases enclosing a practically solid core of growing leaf-blade, becomes gradually thicker and longer: the short basal stem tends to rot away below but grows gradually at the upper end, where new adventitious roots emerge. After a time (eighteen months of artificially shortened days in one experiment) an inflorescence emerges ; further leaf production is then carried on by an axillary bud: this mode of growth without bulb formation has continued for more than three years in the experiment cited.

Under natural conditions, however, the daylength ultimately attains a critical value at which a bulb begins to form; that this is a response to the 